\title{
Cauda equina entrapment in a pseudomeningocele after lumbar Schwannoma extirpation
}

\author{
D. L. Marinus Oterdoom • Rob J. M. Groen • \\ Maarten H. Coppes
}

Received: 4 August 2009/Revised: 11 October 2009/Accepted: 5 November 2009/Published online: 19 November 2009

(C) The Author(s) 2009. This article is published with open access at Springerlink.com

\begin{abstract}
Incidental or intentional durotomy causing cerebrospinal fluid (CSF) leakage, leading to the formation of a pseudomeningocele is a known complication in spinal surgery. Herniation of nerve roots into such a pseudomeningocele is very rare, but can occur up to years after initial durotomy and has been described to cause permanent neurologic deficit. However, cauda equina fiber herniation and entrapment into a pseudomeningocele has not been reported before. Here, we present a case of symptomatic transdural cauda equina herniation and incarceration into a pseudomeningocele, 3 months after extirpation of a lumbar Schwannoma. A 59-year-old man, who previously underwent intradural Schwannoma extirpation presented 3 months after surgery with back pain, sciatica and loss of bladder filling sensation caused by cauda equina fiber entrapment into a defect in the wall of a pseudomeningocele, diagnosed with magnetic resonance imaging. On re-operation, the pseudomeningocele was resected and the herniated and entrapped cauda fibers were released and replaced intradurally. The dura defect was closed and the patient recovered completely. In conclusion, CSF leakage can cause neurological deficit up to years after durotomy by transdural nerve root herniation and subsequent entrapment. Clinicians should be aware of the possibility of this potentially devastating complication. The present case
\end{abstract}

D. L. M. Oterdoom $(\square)$

Department of Neurosurgery, Martini Hospital,

Van Swietenplein 1, 9700 RM Groningen, The Netherlands

e-mail:dlmoterdoom@hotmail.com

R. J. M. Groen · M. H. Coppes

Department of Neurosurgery, University Medical Centre,

State University of Groningen, Groningen, The Netherlands also underlines the importance of meticulous dura closure in spinal surgery.

Keywords Pseudomeningocele - Dura defect . Nerve root entrapment

\section{Case report}

A 59-year-old man presented with a 3-month history of bilateral dorsal leg pain, which aggravated with coughing, sneezing and straining. Because of these complaints, he needed a crutch for walking. Besides from diffuse loss of pin prick sensation in both lower legs, there were no deficits on neurological examination. Magnetic resonance imaging (MRI) revealed an intradural tumor at L3-L4 level, occupying the spinal canal (Fig. 1) and compressing the cauda equina fibers. Through a L3-L4 laminectomy and a midline durotomy, the tumor was removed completely. Dura was closed using a non-resorbable running suture and was sealed with fibrin glue. After 5 days following surgery, the patient was discharged from the neurosurgical department, without neurological deficit and without pain. Histological examination revealed a Schwannoma.

Three months after discharge, the patient was readmitted because of progressive low back and excruciating leg pain, radiating from the right buttock to the foot. Also the patient experienced progressive pain in the tailbone area. Furthermore, there was a loss of bladder filling sensation. On examination, a subcutaneous fluctuating swelling was present at the site of previous lumbar surgery. Compression of this swelling provoked right sided leg pain and pain in the tailbone area. As a consequence, the patient was unable to sleep on his back. MRI revealed a large 


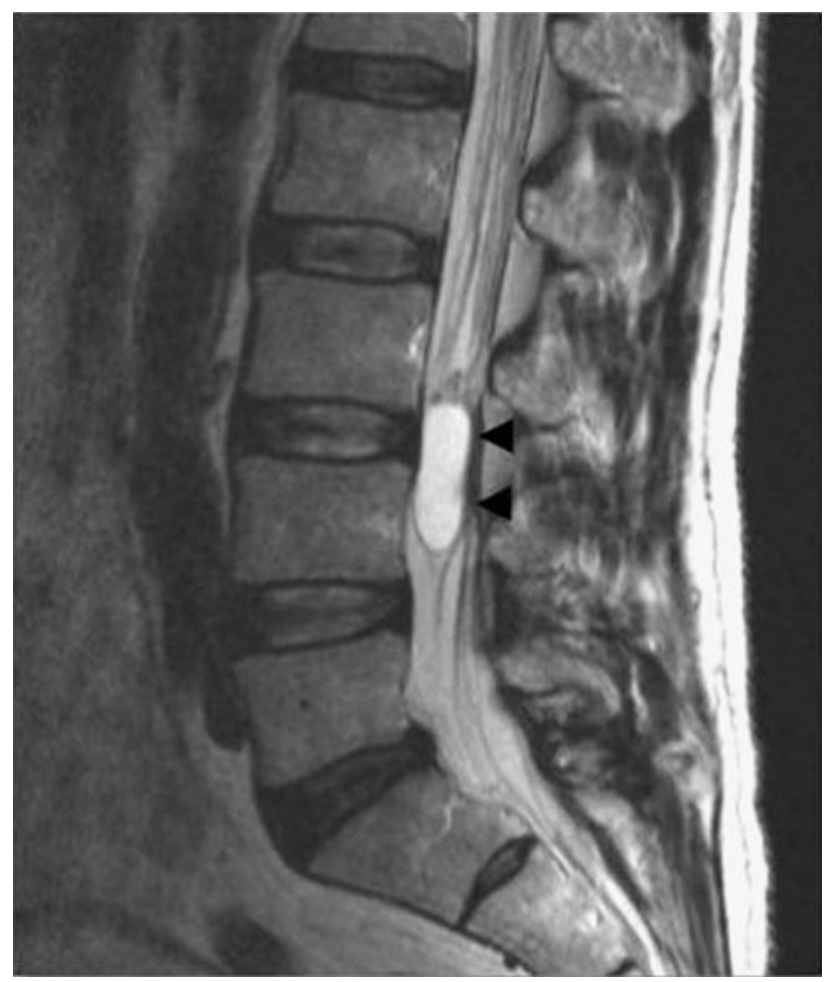

Fig. 1 Preoperative sagittal T2-weighted MRI scan of the lumbar spine showing a hyper-intense intradural tumor (indicated by black arrowheads) at L3-L4 level occupying the complete spinal canal, with the characteristics of a Schwannoma

pseudomeningocele at L4 level. Furthermore, one or more cauda equina fibers appeared to herniate through a small dura defect (Fig. 2).

On re-operation, a pseudomeningocele-containing multiple cauda equina fibers, herniating through a small defect in the thecal sac was identified (Fig. 3). After enlargement of the dura defect, cauda equina fibers were

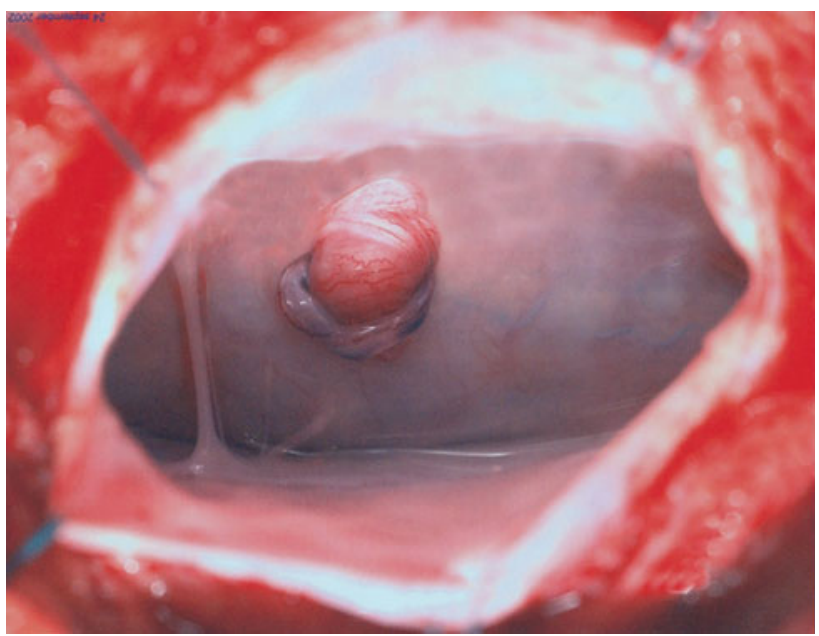

Fig. 3 Intra-operative photograph showing opened pseudomeningocele with transdural herniation of a cluster of edematous cauda equina fibers. The most eccentric fiber shows venous congestion and thrombosis due to incarceration

released and replaced intradurally. The dura was primarily closed and the pseudomeningocele was resected. After 5 days of bed rest, the patient was discharged. At present, 6 years after re-operation, the neurological condition of the patient is excellent.

\section{Discussion}

Complications of extirpation of intradural extramedullary tumors are usually related to problems with wound healing and cerebrospinal fluid (CSF) leakage, although spinal epidural hematomas, intracranial hemorrhage due to acute reduction of CSF pressure, and spinal cord injury have been described $[1,12,13,15]$. Postoperative or posttraumatic
Fig. 2 Postoperative

T2-weighted MRI of the lumbar spine in the sagittal plane (a) and the transversal plane (b) showing a large pseudomeningocele (white arrowheads) at L3-L4 level, containing herniated cauda equina fibers (black arrowhead). White arrows indicate dura and white asterisk indicates spinal canal
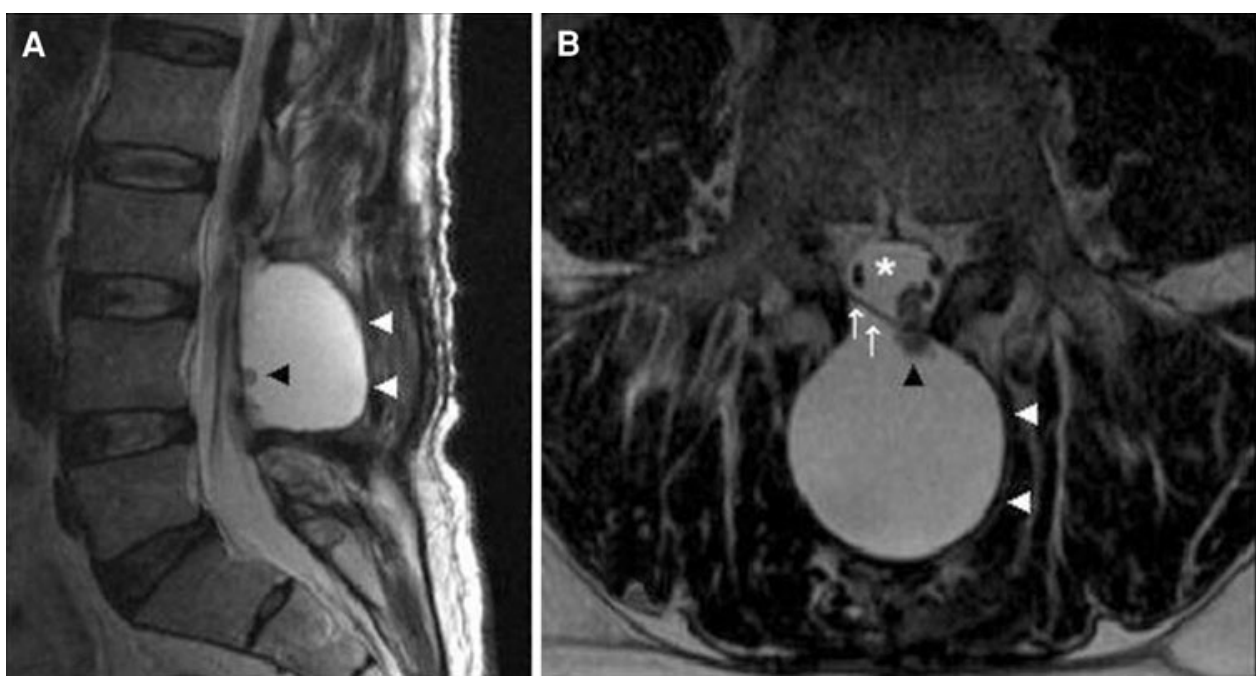
Table 1 Data of nine cases of nerve root herniation into iatrogenic pseudomeningocele

\begin{tabular}{|c|c|c|c|c|c|c|c|}
\hline Number & Author & $\begin{array}{l}\text { Age/ } \\
\text { sex }\end{array}$ & Initial operation & Interval & Symptoms & Surgical findings & Operative result \\
\hline 1 & Hadani [3] & $55 / \mathrm{M}$ & Lam L4, L5 & $14 \mathrm{~d}$ & L5 pain & $\begin{array}{l}\text { Dorsal dura defect, nerve root } \\
\text { herniation and strangulation }\end{array}$ & Recovered \\
\hline 2 & Hadani [3] & $41 / \mathrm{M}$ & Disc L5-S1 & $5 \mathrm{y}$ & L5 pain & $\begin{array}{l}\text { Dorsal dura defect, nerve root } \\
\text { herniation }\end{array}$ & Recovered \\
\hline 3 & Hadani [3] & $41 / \mathrm{M}$ & Lam L3-L5 & $3 \mathrm{y}$ & L4-S1 SM and pain & $\begin{array}{l}\text { Dorsal dura defect, nerve root } \\
\text { herniation and strangulation }\end{array}$ & L5 M \\
\hline 4 & Kothbauer [4] & $60 / \mathrm{F}$ & Disc L4-L5 & $1 \mathrm{~d}$ & L5 SM and pain & $\begin{array}{l}\text { Ventral dura defect, cauda } \\
\text { equina herniation }\end{array}$ & Recovered \\
\hline 5 & Nishi [5] & $63 / \mathrm{M}$ & Disc L3-L4, Lam L4, L5 & $9 \mathrm{~d}$ & $\mathrm{~S} 1$ pain & $\begin{array}{l}\text { Unspecified dura defect, nerve } \\
\text { root herniation }\end{array}$ & Recovered \\
\hline 6 & O'Connor [6] & $16 / \mathrm{F}$ & Disc L4-L5 & $8 \mathrm{y}$ & L5 S and pain & $\begin{array}{l}\text { Dorsal dura defect, nerve root } \\
\text { herniation }\end{array}$ & Recovered \\
\hline 7 & Pavlou [7] & $59 / \mathrm{F}$ & Disc L4-L5 & $7 \mathrm{y}$ & Bilat L5 $\mathrm{M}$ and pain & $\begin{array}{l}\text { Dorsal dura defect, nerve root } \\
\text { herniation }\end{array}$ & Recovered \\
\hline 8 & Töppich [11] & $62 / \mathrm{F}$ & Disc L4-L5 & $5 \mathrm{~d}$ & S1 pain & $\begin{array}{l}\text { Ventral dura defect, nerve root } \\
\text { herniation }\end{array}$ & S1 SM \\
\hline 9 & Töppich [11] & $78 / \mathrm{M}$ & Disc L4-L5 & $4 \mathrm{~d}$ & L5 $\mathrm{S}$ and pain & $\begin{array}{l}\text { Ventral dura defect, nerve root } \\
\text { herniation }\end{array}$ & L5 M \\
\hline
\end{tabular}

$M$ male, Lam laminectomy, $L$ lumbar, $d$ day, Disc discectomy, $S$ sacral, $y$ year, $S M$ sensory and motor deficit, $F$ female, Bilat bilateral, $M$ motor deficit, $S$ sensory deficit

(lumbar puncture) CSF leakage can result in pseudomeningocele formation. A pseudomeningocele is defined as an extradural CSF collection that results from a tear of the dura and subsequent CSF leakage [4]. The majority of pseudomeningoceles result from incidental durotomy during spinal surgery, which in some cases remains unnoticed to the surgeon at the time of operation. Reported incidences vary from 0.3 to $13 \%$ in frequently performed procedures like laminectomy and lumbar disc surgery [2]. Incidence of pseudomeningocele formation after intended durotomy for extirpation of intradural tumors is unknown. Chiou et al. [1] reported four cases of CSF leakage in 256 patients (2\%) operated for intradural tumors. More recently, SafaviAbbasi et al. [10] reported eight cases of CSF leakage (6\%) and six (5\%) pseudomeningocele formations in 128 patients operated for spinal Schwannoma. However, true incidences may be higher, because many cases may remain asymptomatic. Management of iatrogenic pseudomeningoceles and CSF fistulas usually begins with bed rest, followed by external lumbar drainage for several days [14]. Drainage for 3-5 days has a success rate over $90 \%$ in the treatment of CSF leakage, but harbors a risk of infection [11]. Ultimately, re-operation for primary closure of the defect may be necessary [6].

A rare, but potentially devastating complication of iatrogenic CSF leakage is entrapment and incarceration of nerve roots at the site of the dura defect $[3,5,7-9,13]$. This can cause irreversible nerve damage through strangulation and may lead to permanent neurological deficit
[3]. So far, only nine cases of nerve root entrapment into an iatrogenic pseudomeningocele have been described. In only one of these cases, MRI was available to preoperatively establish the diagnosis [9]. All cases were re-operated, which resulted in complete recovery in six cases. In three patients, transdural nerve root herniation resulted in permanent neurological deficit. Typically, on re-operation herniated nerve roots were replaced intradurally and the dura was closed, either primarily or with a dura graft (Table 1 for details).

Transdural herniation and entrapment of cauda equina fibers into a pseudomeningocele has not been reported before in the literature. In our present case, incarceration of the cauda equina fibers developed 3 months after operation. Eight weeks postoperative, this patient noticed a subcutaneous swelling. Four weeks later, during an episode of coughing and sneezing, sudden radicular pain occurred in the right leg and progressive pain in his tailbone. The pain became worse, and also problems with micturition occurred. It is most likely that the dura defect initially was plugged with cauda equine fibers. A sudden increase of intrathecal pressure during coughing and sneezing caused herniation of the cauda fibers and entrapment into the relatively small dura defect. Entrapment resulted in venous congestion of (part of) the nerve roots and caused incarceration (Fig. 3). This case underlines the importance of meticulous dura closure, especially in the light of potentially permanent neurological deficit that can be caused by strangulation of neural tissue in the dura defect. As the 
literature shows, this serious complication can occur many years after the initial surgery. Fortunately, our patient made an excellent recovery after reduction of cauda equina herniation and repair of the dura defect. In case of (acute) new nerve root or cauda equina signs and/or symptoms after spinal (intradural) exploration, the clinician should be aware of the possible existence of transdural nerve fiber entrapment. MR imaging is the technique of first choice to detect this rare, treatable, but potentially devastating complication of incomplete spinal dura closure.

Conflict of interest statement None of the authors has any potential conflict of interest.

Open Access This article is distributed under the terms of the Creative Commons Attribution Noncommercial License which permits any noncommercial use, distribution, and reproduction in any medium, provided the original author(s) and source are credited.

\section{References}

1. Chiou Sh-M, Eggert HR, Laborde G, Seeger W (1989) Microsurgical unilateral approaches for spinal tumour surgery: eight years' experience in 256 primary operated patients. Acta Neurochir 100(3-4):127-133

2. Couture D, Branch CL Jr (2003) Spinal pseudomeningoceles and cerebrospinal fluid fistulas. Neurosurg Foc 15(6):1-5

3. Hadani M, Findler G, Knoler N, Tadmor R, Sahar A, Shacked I (1986) Entrapped lumbar nerve root in pseudomeningocele after laminectomy: report of three cases. Neurosurgery 19(3):405-407

4. Hawk MW, Kim KD (2000) Review of spinal pseudomeningoceles and cerebrospinal fluid fistulas. Neurosurg Foc 9(1):e5
5. Kothbauer KF, Seiler RW (2000) Transdural cauda equina incarceration after microsurgical lumbar discectomy: case report. Neurosurgery 47(6):1449-1451

6. Misra SN, Morgan HW, Sedler R (2003) Lumbar myofascial flap for pseudomeningocele repair. Neurosurg Foc 15(3):1-5

7. Nishi S, Hashimoto N, Takagi Y, Tsukahara T (1995) Herniation and entrapment of a nerve root secondary to an unrepaired small dural laceration at lumbar hemilaminectomies. Spine 20(23): 2576-2579

8. O'Connor D, Maskery N, Granville Griffiths WE (1998) Pseudomeningocele nerve root entrapment after lumbar discectomy. Spine 23(13):1501-1502

9. Pavlou G, Bucur SD, van Hille PT (2006) Entrapped spinal nerve roots in a pseudomeningocele as a complication of previous spinal surgery. Acta Neurochir (Wien) 148(2):215-219

10. Safavi-Abbasi S, Senoglu M, Theodore N, Workman RK, Gharabaghi A, Feiz-Erfan I et al (2008) Microsurgical management of spinal schwannomas: evaluation of 128 cases. J Neurosurg spine 9(1):40-47

11. Shapiro SA, Scully T (1992) Closed continuous drainage of cerebrospinal fluid via a lumbar subarachnoid catheter for treatment or prevention of cranial/spinal cerebrospinal fluid fistula. Neurosurgery 30(2):241-245

12. Thomas G, Jayaram H, Cudlip S, Powell M (2002) Supratentorial and infratentorial intraparenchymal hemorrhage secondary to intracranial CSF hypotension following spinal surgery. Spine 27(18):E410-E412

13. Töppich HG, Feldmann G, Sandvoss G, Meyer F (1994) Intervertebral space nerve root entrapment after lumbar disc surgery. Spine 19(2):249-250

14. Waisman M, Schweppe Y (1991) Postoperative cerebrospinal fluid leakage after lumbar spine operations. Conservative treatment. Spine 16(1):52-53

15. Yi S, Yoon do H, Kim KN, Kim SH, Shin HC (2006) Postoperative spinal epidural hematoma: risk factor and clinical outcome. Yonsei Med J 47(3):326-332 